\title{
Cell membrane estrogen receptors resurface
}

To the editor-In their recent and informative News and Views "Estrogen hits the surface," Collins and Webb ${ }^{1}$ suggested that "newly discovered estrogen receptordependent signaling pathways demonstrate that estrogen functions in the cytosol as well as in the nucleus." Although we agree wholeheartedly with the data cited, we regret that the authors failed to acknowledge that cell surface forms of estrogen receptors coupled to intracellular signaling pathways were first reported more than 20 years ago $^{2-4}$. Thus, this work is not so much newly discovered as rather newly recognized due to profound deficiencies in the capacity of the nuclear transcription factor concept to integrate all aspects of estrogen action.

As noted by Collins and Webb ${ }^{1}$, reports of rapid estrogen effects occurring in vasculature, breast, bone, uterus and neuronal tissues cannot be explained by prevailing theories. Yet it is still widely believed that the biological activity of estrogen in responsive cells is mediated only through a specific high-affinity es- trogen receptor located exclusively in their nuclei. On binding estrogen, the nuclear receptor promotes association with target genes and permits regulation of selective gene transcription ${ }^{5}$. However, in addition to the latter pathway, it has been established that estrogen can also induce extremely rapid increases in the levels of intracellular second messengers, including calcium and cAMP, as well as activation of mitogen-activated protein kinase and phospholipase $^{1-4}$. The time course of these acute events parallels that elicited by peptides, lending support to the hypothesis that they do not involve the 'classical' genomic action of estrogen. Many of the rapid effects of estrogen are now attributed to the action of the hormone at the cell membrane, and these biologic actions seem to be mediated by membrane receptors that bind estrogen. The newer literature discussed by Collins and Webb should be evaluated in the fuller context of the substantial background in this field.

\section{Viral phenotype and CCR5 genotype}

To the editor-We thank D'Aquila et al. ${ }^{1}$ for their comments on our recent News and Views article ${ }^{2}$. We fully agree that both CXCR4 and CCR5 inhibitors should be evaluated in clinical trials, if suitable compounds are developed. However, we wish to clarify some aspects of the literature raised by D'Aquila et al. on the emergence of CXCR4-using syncytium-inducing (SI) HIV-1 strains in vivo. First, the study we cited $^{3}$ for the lack of association of the SI viral phenotype with heterozygosity for CCR5 $\triangle 32$ was not, in fact, a study of "newly infected patients." The subcohort of 406 HIV-1-infected subjects examined in that study was seroprevalent with an average time to AIDS of 5.8 years, compared with 9-10 years as seen in seroincident cohorts $^{3}$. Moreover, although D'Aquila et al. did indeed find an association of the SI viral phenotype with CCR5 $\triangle 32$ heterozygosity in their study of 95 individuals ${ }^{4}$, larger studies have either not confirmed this observation ${ }^{5}$ or have found a non-statistically significant trend ${ }^{6}$. On these last points, we look forward to the results of meta-analysis (ref. 7 and T. O'Brien, personal communication) to provide more definitive evidence as to whether there is any association of viral phenotype and chemokine receptor genotype.

NELSON L. MiCHAEL ${ }^{1} \&$

JOHN P. MOORE ${ }^{2}$

${ }^{1}$ Division of Retrovirology, Walter Reed Army Institute of Research, 1600 E. Gude Drive

Rockville, Maryland 20850, USA

Email: nmichael@pasteur.hjf.org

${ }^{2}$ The Aaron Diamond AIDS Research Center The Rockefeller University, 455 First Avenue New York, New York 10016, USA

1. D'Aquila, R.T., Hughes, M. \& Johnson, V.A. HIV-1 entry inhibitors and virus emergence. Nature Med. 5, 1091 (1999).

2. Michael, N.L. \& Moore, I.P. HIV-1 entry inhibitors: evading the issue. Nature Med. 5, 740-742 (1999).

3. Michael, N.L. et al. The role of viral phenotype and CCR-5 gene defects in HIV-1 transmission and disease progression. Nature Med. 3, 338-340 (1997)

4. D'Aquila, R.T. et al. CCR5/delta(ccr5) heterozygosity: a selective pressure for the syncytium-inducing human immunodeficiency virus type 1 phenotype. NIAID AIDS Clinical Trials Group Protocol 241 Virology Team. J. Infect. Dis. 177, 1549-1553 (1998).

5. de Roda Husman, A.M. et al. Association between CCR5 genotype and the clinical course of HIV-1 infection. Ann. Intern. Med. 127, 882-890 (1997).

6. Bratt, G. et al. MT-2 tropism and CCR5 genotype strongly influence disease progression in HIV-1 infected individuals. AIDS 12, 729-736 (1998).

7. Ioannidis, I.P.A. et al. Genetic effects on HIV disease progression. Nature Med. 4, 536-537 (1998).

\author{
Richard J. PIETRAS ${ }^{1} \&$ \\ Clara M. SZEGO ${ }^{2}$ \\ 'UCLA School of Medicine, Department of \\ Medicine-Hematology/Oncology \\ Los Angeles, California 90095-1678, USA \\ ${ }^{2}$ University of California \\ Department of Molecular, Cell \& \\ Developmental Biology \\ Los Angeles, California 90095-1606, USA
}

Collins and Webb reply-In no way did we intend to give the impression that estrogen receptors on the surface of plasma membranes or intracellular coupling was a new concept.

Our News \& Views discussed a recent paper $^{6}$ that clearly stated that the existence of a putative membrane estrogen receptor is supported by studies spanning 20 years and that the origin and functions of this receptor are not well defined. Indeed this was the main thrust of our article. We wanted to convey that the surface estrogen receptor couples to a common intracellular signaling pathway in four different cells, as illustrated in our figure. These data reinforce the rapid, non-genomic estrogen-receptor dependent mechanisms of estrogen.

It is noteworthy that the research community is expanding the function of steroid hormone receptors beyond the confines of sexual differentiation and reproductive endocrine function. Gaining a better understanding of the rapid actions of estrogen may lead to new therapeutic strategies for the treatment of cell proliferative, neurodegenerative and cardiovascular defects.

\section{Peter Collins \& Carolyn WebB} Imperial College School of Medicine National Heart \& Lung Institute

London, SW3 6LY, UK

Email:Peter.collins@ic.nc.uk

1. Collins, P. \& Webb, C. Estrogen hits the surface. Nature Med. 5, 1130-1131 (1999).

2. Pietras, R. \& Szego, C. Endometrial cell calcium and oestrogen action. Nature 253, 357-359 (1975).

3. Pietras, R. \& Szego C. Specific binding sites for oestrogen at the outer surfaces of isolated endometrial cells. Nature 265, 69-72 (1977).

4. Wehling, M. Specific, nongenomic actions of steroid hormones. Annu. Rev. Physiol. 59, 365-393 (1997).

5. Tsai, M. et al. in Williams Textbook of Endocrinology $9^{\text {th }}$ Edition (eds. Wilson, J. et al.) 55-94 (Harcourt Brace, London, 1998)

6. Razandi, M., Pedram, A., Greene, G.L. \& Levin, E.R. Cell membrane and nuclear estrogen receptors (ERs) originate from a single transcript: studies of ER alpha and ER beta expressed in Chinese hamster ovary cells. Mol. Endocrinol. 13, 307-319 (1999). 